\title{
AN INVESTIGATION OF MINERALOGY AND MICROSCOPIC STRUCTURE IN KERMAN CITY SEDIMENTS
}

\author{
Mohammad Reza Aminizadeh Bazanjani ${ }^{1}$--- Golam Reza Lashkaripour ${ }^{2}$--- \\ Mohammad Ghafoori $^{3}$--- Naser Hafezi Moghadas ${ }^{4}$ \\ ${ }^{1,2, s, t}$ Department of Geology, Ferdowsi University of Mashhad, Iran
}

\begin{abstract}
In this research, the microscopic structure and mineralogical changes of the soils within Kerman city have been studied. To assess compactness, consolidation and structural characteristics of sedimentary deposits, the authors used the comparing results of scanning electron microscopy (SEM) images in natural and reconstituted soils of Kerman city arena. To study the microstructure of Kerman soils, about 15 soil samples from different depths and locations were prepared and sent to the central electron microscopic laboratory in Ferdowsi University of Mashad. Selected areas were planned in such a way that they have good distribution in Kerman city confine. To understand soil structure some of the samples were reconstituted with moisture content higher than liquid limit as a result of which the post sedimentation structure was demolished. Then images of natural and reconstituted samples were compared with each other. The required tests were performed on samples in Central laboratory of Mashhad University, Iran. Using the energy dispersive X-ray spectroscopy technique (EDX or EDS) chemical composition of the samples was determined to form of point. Having identified the chemical composition of minerals and compared them with typical samples, the name of soil minerals in Kerman soils was determined.
\end{abstract}

Keywords: Microscopic structure, Scanning electron microscopy, Kerman, sedimentary basin, microstructure, energy dispersive X-ray

Received: 8 August 2013/ Revised: 28 September 2013/ Accepted: 3 October 2013/ Published: 7 October 2013

\section{INTRODUCTION}

Clay minerals are hydrous silicates of aluminum and magnesium which have formed a complex layered structure owing its formation to the basic unit of either tetrahedral silica or octahedral alumina. Depending on how the structural units are connected to each other, different types of clay minerals will be formed. The combination of silica tetrahedral units produces a sheet silicate and the combination of aluminum octahedral units produces octahedral sheets called Gibbsite. Gibbsite and silica units are combined in various forms and create a strong ionic 
connection, thus forming different types of clay soils (Rahimi, 2005). The origin of clay minerals depends on the source of rock, environmental chemistry, weathering processes and sedimentation mechanism (Ehrmann et al., 2005).

Furthermore, the processes of transportation and sedimentation have an important role in the formation of clay minerals (Amjad et al., 2011). In recent years, clay minerals have been used to identify the sources of different sediment formations in the river, lacustrine and marine basin (Khoddami et al., 2006). Fine sands and silts are often considered as the byproducts of mechanical comminuting of coarser particles due to the passing of time in the fluvial system, or grinding in glacier fed rivers (Thomas, 2003). Due to difficulties in handling natural soils and the advantages offered by artificial specimens, much fundamental framework research in soil mechanics has been developed by reconstituted or artificial specimens (Maccarini, 1987; Bressani, 1990; Huang and Airey, 1991; Coop and Atkinson, 1993; Haeri et al., 2006). The mechanical properties of natural soils are outcome of complex interaction with surrounding environment (Buscarnera and Nova, 2011). To demonstrate the existence of cementation between soil particles, experimental and theoretical study on natural and reconstituted samples has been carried out by use of compression tests (Ciro et al., 2011). Clays generated by surface weathering and shallow digenetic processes are transformed into mature clay mineral assemblages in the mud rocks that founded in sedimentary basins (Richard, 2005).

Therefore identification of clay minerals related to sedimentary environment and its role in the formation of sediments is of great importance. This research uses the microscopic electron images of minerals to identify the soils of Kerman city sediments.

\subsection{Sedimentary basin model of Kerman}

Kerman city is located in south east of Iran in the north of Kerman plain (figure 1). The Physiographic shape of Kerman plain's sedimentary basin was obtained due to tectonic movements of Quaternary period. Kerman plain is located in depression between KuhbananMahan mountain ranges in the east and Badamo-Davaran in the west and has a Graben structure formed by circumferential reverse faults (Figure 1). Kerman city is a part of Kerman plain and, in the present research; all of the assessment and analysis were done in Kerman city soils. Kerman deposits are constituted of fine grained alluvial materials that are mainly silt and clay (CL-ML). Kerman plain, during Pleistocene and four major glacial periods as a closed basin, received all the flood sediments that were issued from high areas. Transportation and deposition of flood materials has been done proportional to flood energy in depression and low land areas and has formed Kerman plain. . In upper Pleistocene, due to tectonic movements, conditions of closed basin has been varied and Kerman sedimentary basin gently sloped to the north and north-west direction (Kadjar, et al. 1996). 
Figure-1. Situation and Geological sedimentary basin map of Kerman area

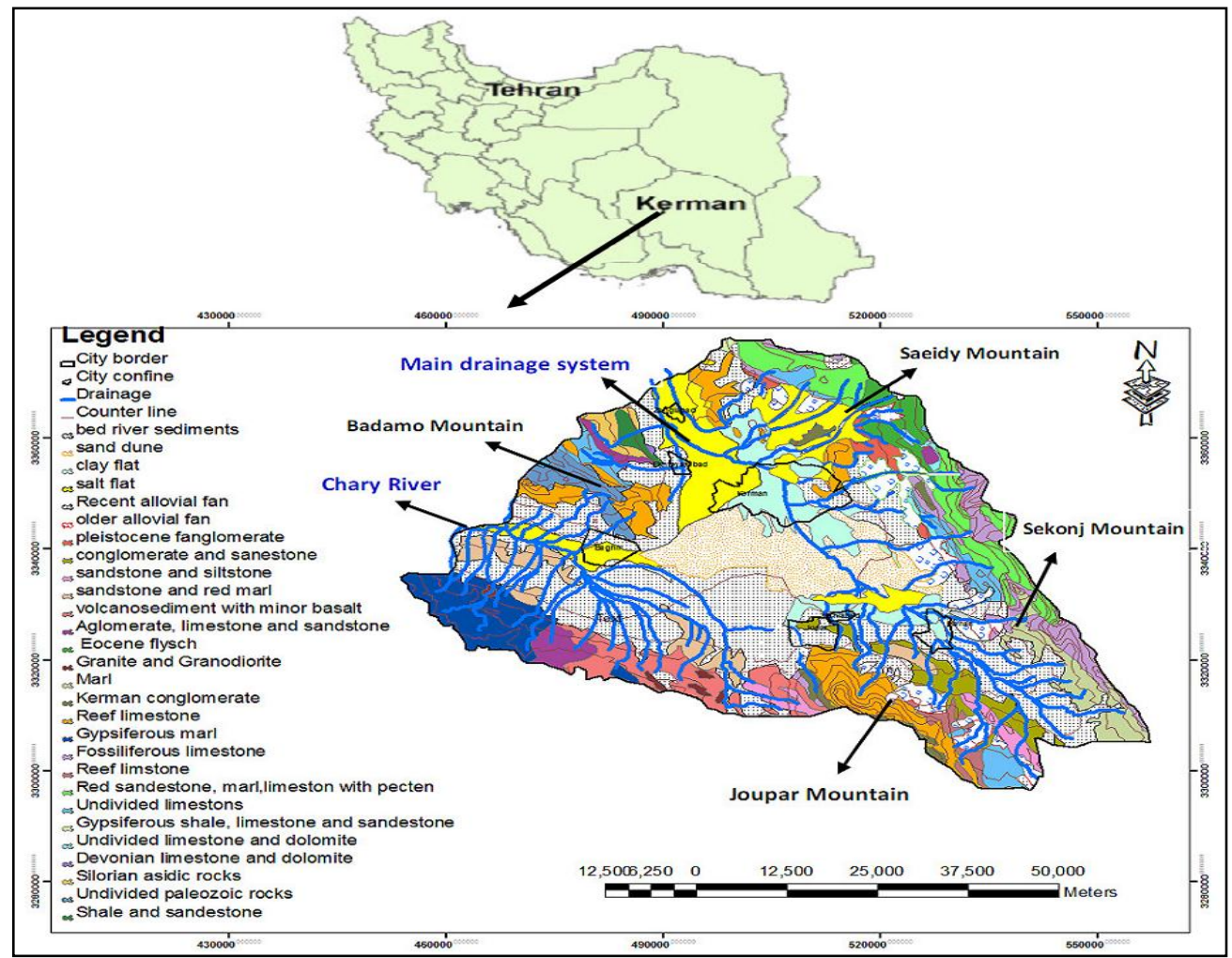

\section{MATERIALS AND METHODS}

In this research the microscopic properties and mineralogical changes of Kerman soils are studied. Scanning electron microscopy is used as an instrument to diagnose soil structure and determine the types of minerals present in the Kerman soils. This tool uses the electron beam to illustrate the image and is able to process the topography, morphology and mineral composition of soil samples. The resolution ability of electron microscopy (SEM) is less than $1 \mathrm{~nm}$ and its magnification powers are equal to 400,000 times. To study the microstructure soils of Kerman, about 15 soil samples from different depths and locations were prepared and some of the samples were reconstituted with moisture content more than liquid limit. Then images of natural and reconstituted samples were compared with each other. The required tests were performed on samples in Central laboratory of Mashhad University. Using the energy dispersive X-ray spectroscopy technique (EDX) and chemical composition of the samples was determined in form of point. Having identified the chemical composition of minerals and compared them with typical samples, the name of soil minerals in the Kerman city soils was specified. Considering that the water is evaporated in vacuum in the process of preparing samples, at first water must be separated from the soils. Materials that are non-metals, like gold, must be coated by a thin layer of conduction, this action can be done using an instrument called coverer and to achieve such an aim, electricity and argon gas were used. The argon ions were attracted to negatively charged 
gold foil and gold atoms forming a very thin layer located on the surface of the soil samples prevented the electrons to penetrate into the soils.

\section{DISCUSSION}

3.1. Microstructure and Chemical Analysis (EDX) in Kerman Soils Using (SEM) Images

The microscopic components of soil are named microstructure and Normally, microstructure depends on micro fabric, composition, and bonding between the soil grains. Overall, in the microstructure analysis four components such as grain geometry, fabric, porosity, and the cement between the grains are coincided. One of the most powerful tools for micro structural analysis is scanning electron microscopy (SEM).To study the microstructure soils in Kerman city confine, about 15 soil samples from different depths and locations were prepared and sent to the central electron microscopic laboratory of Ferdowsi University. Selecting areas were planned in such a way that they have good distribution in Kerman city area (Figure 2). The required tests were performed in Central laboratory of Mashhad University and Chemical composition of the samples was determined using the energy dispersive X-ray spectroscopy technique (EDX or EDS). Having identified the chemical composition of minerals, and compared them with typical samples, the name of soil minerals was determined in the Kerman city arena. Characteristics of site that electron microscopy experiments have been performed in Kerman are recorded in Table 1.

Using the energy dispersive X-ray spectroscopy technique (EDX), chemical composition of the samples was determined to form the point (Welton, 1950). Results of electron microscopy images and chemical analysis of tested samples are shown in Figures (3 to 8). The dominant minerals in sedimentary deposits of the Kerman city range were identified by comparing them and their picks with typical samples.

Figure-2. Position of points that scanning electron microscopy tests have been performed

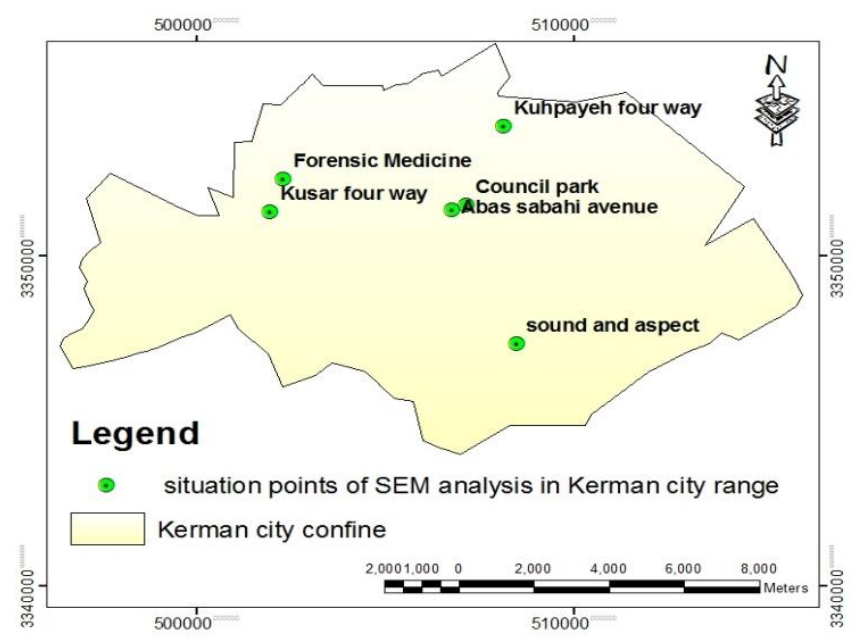




\subsection{Minerals Present in the Soils of Kerman}

Based on the results of qualitative analysis (EDX) and according to the elements existed in Kerman sediments, the dominant minerals in sedimentary deposits of the Kerman range were identified by comparing their picks with type samples (Welton, 1950).

Table- 1. Characteristics of sites that electron microscopy experiments have been performed

\begin{tabular}{|l|l|l|l|l|l|}
\hline No & Site Location & Latitude & Longitude & $\begin{array}{l}\text { Depth } \\
(\mathbf{m})\end{array}$ & Sample condition \\
\hline $\mathbf{1}$ & South Este Diamond structure & $\mathbf{5 0 5 0 7 6}$ & $\mathbf{3 3 5 0 5 8 8}$ & $\mathbf{3 0}$ & undisturbed sample \\
\hline $\mathbf{2}$ & South Este Diamond structure & $\mathbf{5 0 5 0 7 6}$ & $\mathbf{3 3 5 0 5 9 0}$ & $\mathbf{4 0}$ & undisturbed sample \\
\hline $\mathbf{3}$ & Kuhpayeh four way & $\mathbf{5 0 8 1 7 9}$ & $\mathbf{3 3 5 3 9 2 5}$ & $\mathbf{1 3}$ & undisturbed sample \\
\hline $\mathbf{4}$ & Sound and aspect administration & $\mathbf{5 0 8 5 1 7}$ & $\mathbf{3 3 4 6 7 6 3}$ & $\mathbf{1 0}$ & undisturbed sample \\
\hline $\mathbf{5}$ & Forensic medicine & $\mathbf{5 0 2 3 3 0}$ & $\mathbf{3 3 5 2 3 2 4}$ & $\mathbf{8}$ & $\begin{array}{l}\text { Reconstituted with water } \\
\text { content 1.5 times liquid limits }\end{array}$ \\
\hline $\mathbf{6}$ & Forensic medicine & $\mathbf{5 0 2 3 3 0}$ & $\mathbf{3 3 5 2 3 2 4}$ & $\mathbf{1 0}$ & $\begin{array}{l}\text { Reconstituted with water } \\
\text { content 1.5 times liquid limits }\end{array}$ \\
\hline 7 & Forensic medicine & $\mathbf{5 0 2 3 3 0}$ & $\mathbf{3 3 5 2 3 2 4}$ & $\mathbf{1 4}$ & $\begin{array}{l}\text { Reconstituted with water } \\
\text { content 1.5 times liquid limits }\end{array}$ \\
\hline $\mathbf{8}$ & Forensic medicine & $\mathbf{5 0 2 3 3 0}$ & $\mathbf{3 3 5 2 3 2 4}$ & $\mathbf{1 6}$ & undisturbed sample \\
\hline $\mathbf{9}$ & Forensic medicine & $\mathbf{5 0 2 3 3 0}$ & $\mathbf{3 3 5 2 3 2 4}$ & $\mathbf{3 0}$ & undisturbed sample \\
\hline 10 & Council park & $\mathbf{5 0 7 1 8 3}$ & $\mathbf{3 3 5 1 5 3 0}$ & $\mathbf{1 0}$ & undisturbed sample \\
\hline 11 & Council park & $\mathbf{5 0 7 1 8 3}$ & $\mathbf{3 3 5 1 5 3 0}$ & $\mathbf{3 0}$ & undisturbed sample \\
\hline 12 & Baghodrat four way & $\mathbf{5 0 6 5 9 1}$ & $\mathbf{3 3 4 7 8 2 7}$ & $\mathbf{1 8}$ & undisturbed sample \\
\hline 13 & abas sabahy avenue & $\mathbf{5 0 6 8 1 8}$ & $\mathbf{3 3 5 1 3 8 3}$ & $\mathbf{8}$ & undisturbed sample \\
\hline 14 & abas sabahy avenue & $\mathbf{5 0 6 8 1 8}$ & $\mathbf{3 3 5 1 3 8 3}$ & $\mathbf{1 4}$ & undisturbed sample \\
\hline 15 & Sound and aspect administration & $\mathbf{5 0 8 5 1 7}$ & $\mathbf{3 3 4 7 3 4 6}$ & $\mathbf{4}$ & undisturbed sample \\
\hline
\end{tabular}

\subsubsection{Illite (K1-1.5Al4 [Si7-6.5Al1-1.5O20] (OH) 4)}

Illite is a non-expanding, clay-sized, microscopic mineral. Illite is a phyllosilicate or layered alumino-silicate. Its structure is constituted by the repetition of tetrahedron - octahedron tetrahedron (TOT) layers. Illite minerals, has quartz and calcite detritus grains and in semiquantitative analysis (EDX) its principal elements include of $\mathrm{Fe}, \mathrm{Ca}, \mathrm{MG}$ with small amount of $\mathrm{K}$, $\mathrm{Al}$, SI. It is noteworthy that the relative height of $\mathrm{K}$ in the Illite EDX spectrum is typically less than Al. Illite formation conditions can be considered in relationship with the cycles of redeposition and watering of sediments leaching from feldspars and muscovite (HosseiniBarzi, 2010). Illite minerals are recorded in South East Diamonds, Forensics medicine and Council park sites.

\subsubsection{Chlorite ((Mg, Al, $\mathrm{Fe}) 12[(\mathrm{Si}, \mathrm{Al}) 8 \mathrm{O} 20](\mathrm{OH}) 16)$}

Chlorite is the group name for about 10 related minerals. However, the term Chlorite can be used both to describe the group in general, and as a specific term to describe any green member of the Chlorite group whose exact identity is not practical to be determined. Chlorite is very common, and is often an uninteresting green mineral coating the surface of more important minerals. In semi-quantitative EDX analysis, their major elements include $\mathrm{Si}, \mathrm{Al}, \mathrm{Mg}$, and $\mathrm{Fe}$ that its amount is usually variable. In identification of this mineral, existence of the main component and relative peak height of elements are important. Abundance of chlorite has been found in the following sites in Kerman: sound and aspect site, AbasSabahi Street, Baghodrat four way and Kuhpayeh four way. 


\subsubsection{Smectite $\{(1 / 2 \mathrm{Ca}, \mathrm{Na}) 0.7(\mathrm{Al}, \mathrm{Mg}, \mathrm{Fe}) 4[(\mathrm{Si}, \mathrm{Al}) 8 \mathrm{O} 20] * \mathrm{nH} 2 \mathrm{O}\}$}

Smectites are one of the most important groups of phyllositicates found in soils and sediments, and certainly their study is most difficult. New information about the formation mechanisms, impact of structural features on surface properties, and long-term stability of smectites can best be gained from the systematic study of single-phase specimen's . In most instances, these specimens can only be obtained through synthesis under controlled conditions. Smectite is the name of a group of clay minerals that has three structural layers, so that a thin layer of octahedral aluminum in form of sandwich locates between two silica tetrahedral. In semiquantitative analysis (EDX) its principal elements include $\mathrm{SI}, \mathrm{AL}, \mathrm{Ca}, \mathrm{Fe}, \mathrm{Mg}$ with small amount of $\mathrm{Na}$ and $\mathrm{K}$. This mineral is found in the Forensic Medicine and Abbas Sabahi avenue sites.

\subsubsection{Halloysite ( $\left.\mathrm{Al} 2 \mathrm{O} 3 * 2 \mathrm{SiO}_{2} * 4 \mathrm{H} 2 \mathrm{O}\right)$}

The most important members of the kaolin sub group of minerals are kaolinite and halloysite. Halloysite has a similar composition except that it contains additional water molecules between the layers and, most commonly, has a tubular morphology. Halloysite loses its interlayer water very easily so it is often observed in a partly dehydrated state. In semi-quantitative EDX analysis the main of Haloysite components include SI and Al. Halloysite is member of the kaolinite group that its individual layers are separated by sheets of water. In EDX spectrum of the peak height of SI and $\mathrm{Al}$ are approximately equal to each other. Halloysite has been obtained from chemical analysis of feldspar and is a member of double sheet minerals group. These minerals may be content two or four water molecules. Halloysite mineral in Kerman range has been recorded at Forensic Medicine site in depth of 8 meters.

\subsubsection{Illite - smectite}

Illite-smectite interstratified clay minerals are ubiquitous in sedimentary basins and they have been linked to the maturation, migration, and trapping of hydrocarbons, rock cementation, evolution of pore water chemistry during diagnosis and the development of pore pressure. Lllitesmectiteis a mineral combination, because mixed layer clays are composed of more than one clay type whose composition and morphology are variable.

Figure- 3. SEM photomicrographs EDX analysis, south east Diamond Site, depth 40m.
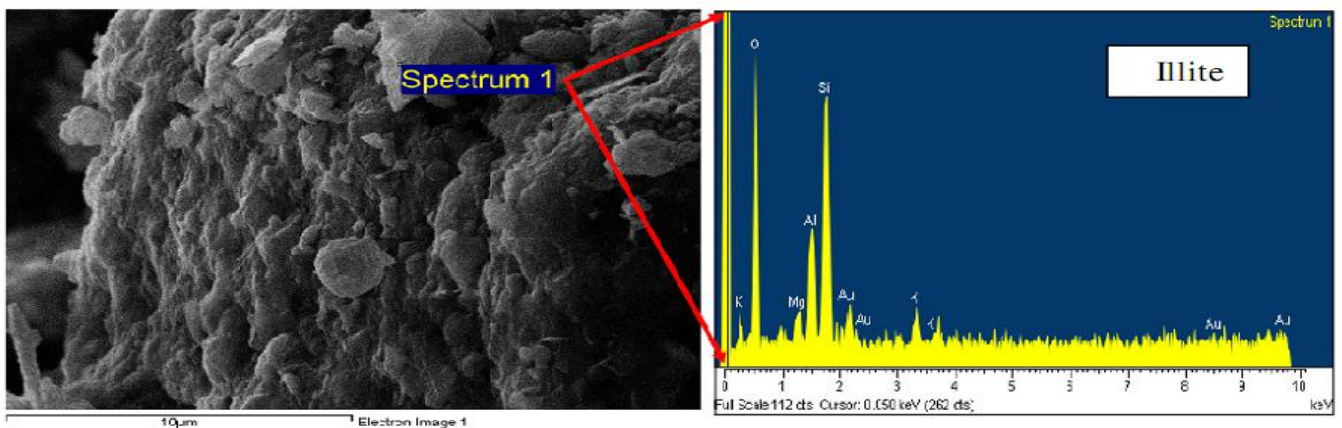
Figure- 4. SEM photomicrographs and EDX analysis sound and aspect Site, depth $10 \mathrm{~m}$.

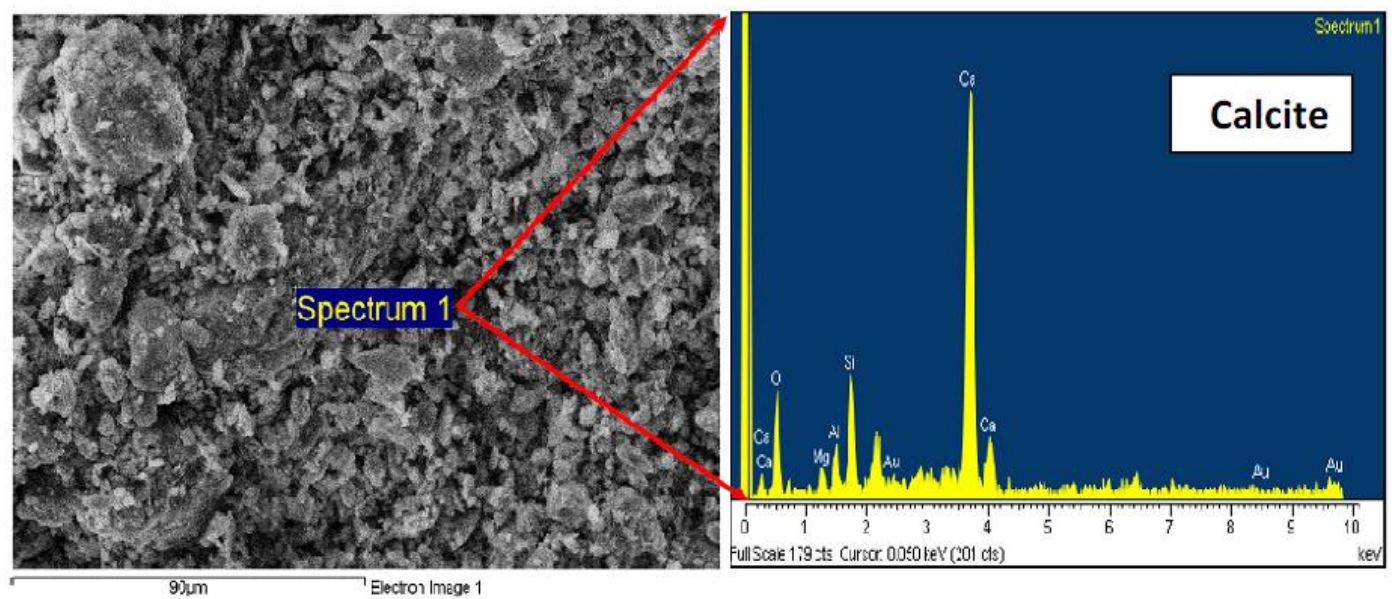

Figure- 5. SEM image and EDX analysis of reconstituted sample, sound and aspect site, depth $8 \mathrm{~m}$.
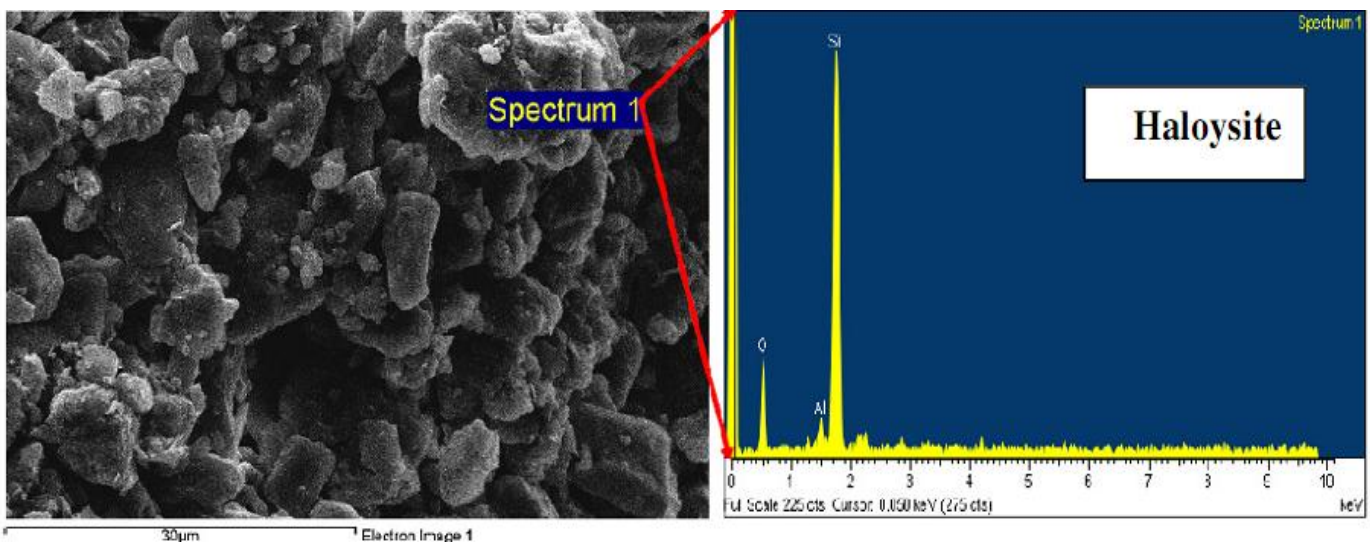

Figure- 6.SEM image and EDX analysis of natural sample, Council park site, depth 30m.

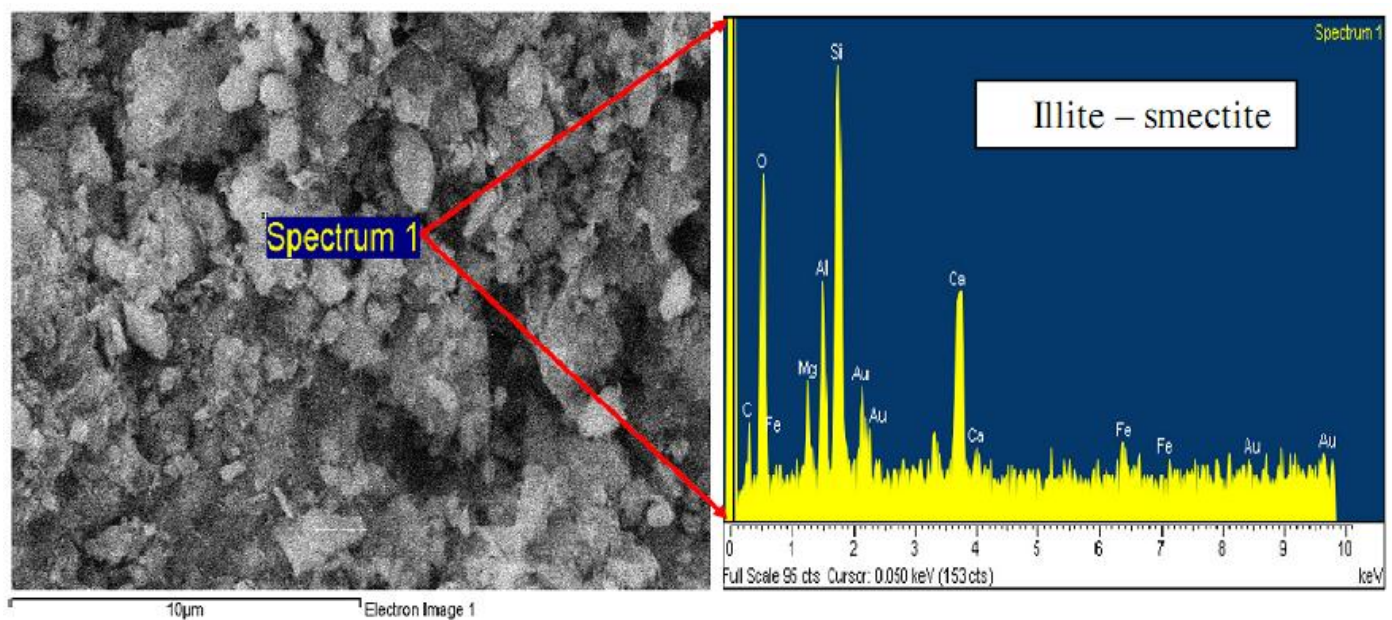


Figure- 7.SEM image and EDX analysis natural sample, Abas Sabahi avenue site, depth $8 \mathrm{~m}$
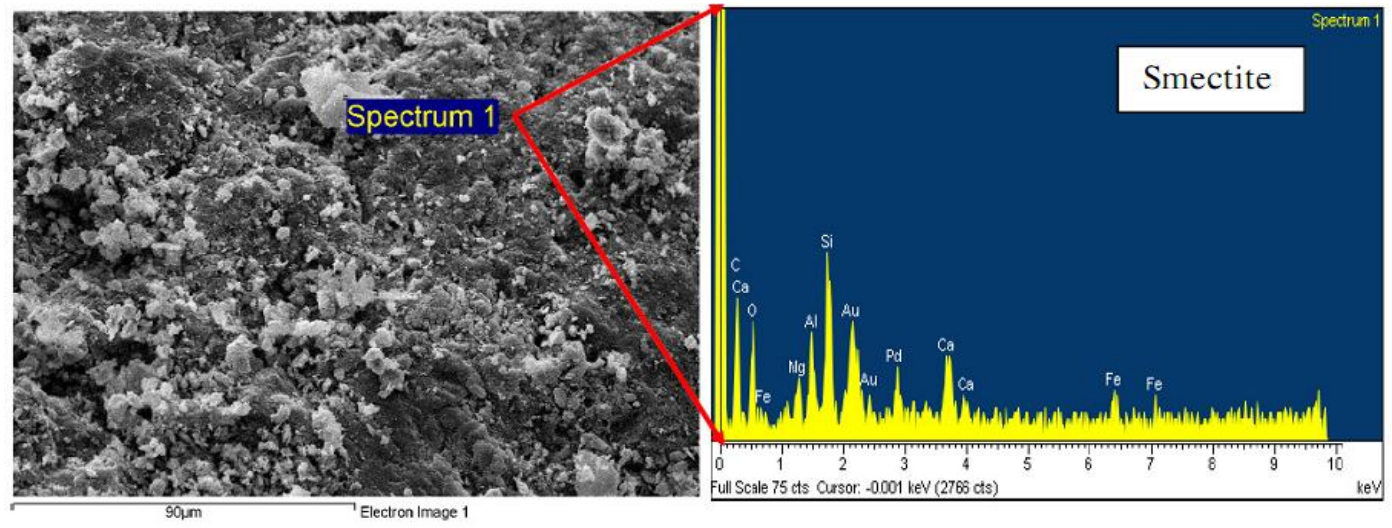

Figure- 8. SEM image and EDX analysis natural sample, Abas Sabahi avenue site, depth $14 \mathrm{~m}$
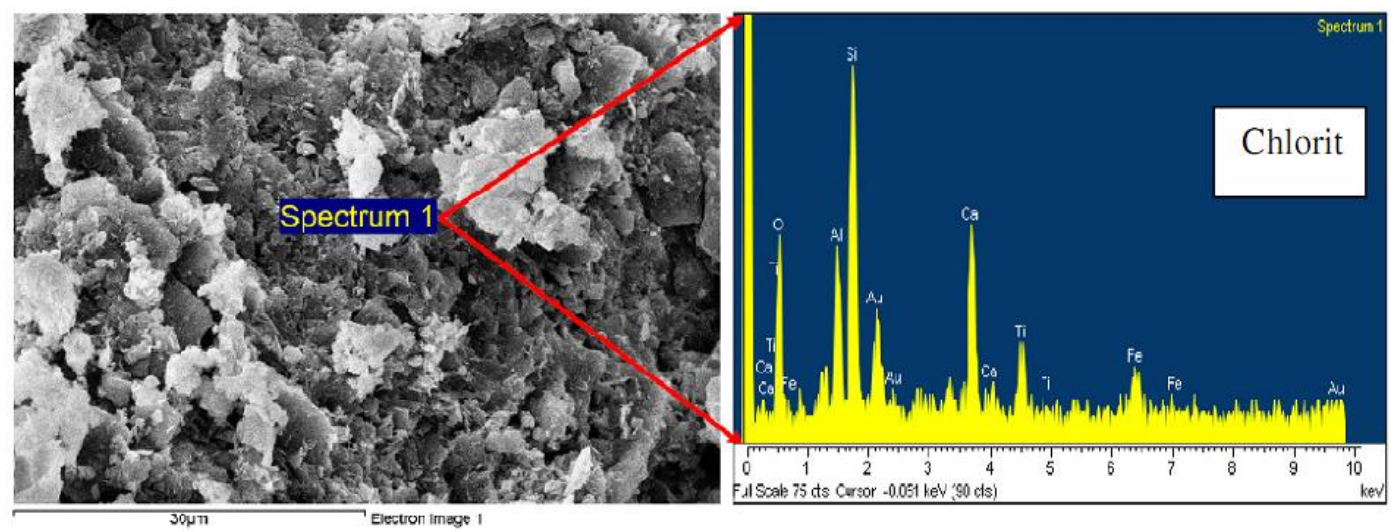

3.3. Evaluation of Structure and Fabric Using Scanning Electron Microscopy (SEM) Images

For evaluation of compactness, consolidation, and structural characteristics of sedimentary deposits in Kerman city arena we used the comparing results of SEM images. Therefore scanning microscopic electron images of natural and reconstituted soils were prepared and compared with each other (Figures 9 to 14). Considering that reconstitution of some samples has been done with water content more than liquid limits (1.25 to 1.5 time of liquid limit), obviously the lack of structure and fabric causes randomly arrangement in the particles. In SEM for reconstituted images, aggregates were attached to each other in form of corner to corner, therefore compaction and density of soil is low and volume of the spaces is relatively high. Considering that maximum pressure exerted on reconstituted samples is $1600 \mathrm{kPa}$, the compacted samples show a normal consolidated state (Figures 10 to 11). In natural samples, compaction and density of soil is much higher in comparison with the reconstruction. So for some sites, a case of orientation and row of grains has been observed (Figures 12 to 14). In some natural instances, the compression and consolidation state is high but pore and voids are very small (Forensic Medicine site). For some natural and undisturbed soil samples, however, the compaction and density of soils is low, thus showing the soil is normally consolidated. Summarizing the results show that fabric and structure 
of Kerman sediment has not been developed high and the soil stability is caused by its compression. Deposits of Kerman city range are often compacted and consolidated and results of consolidation test and scanning electron microscopy images (SEM) confirm this conclusion. Of course, in some samples the bonds between the particles are seen as cementation. Probably due to the transparency and the bright color of these bonds, the cement between the particles can be judged as calcite.

Figure- 9. Photomicrographs of reconstituted soils, forensic medicine site, depth $8 \mathrm{~m}$

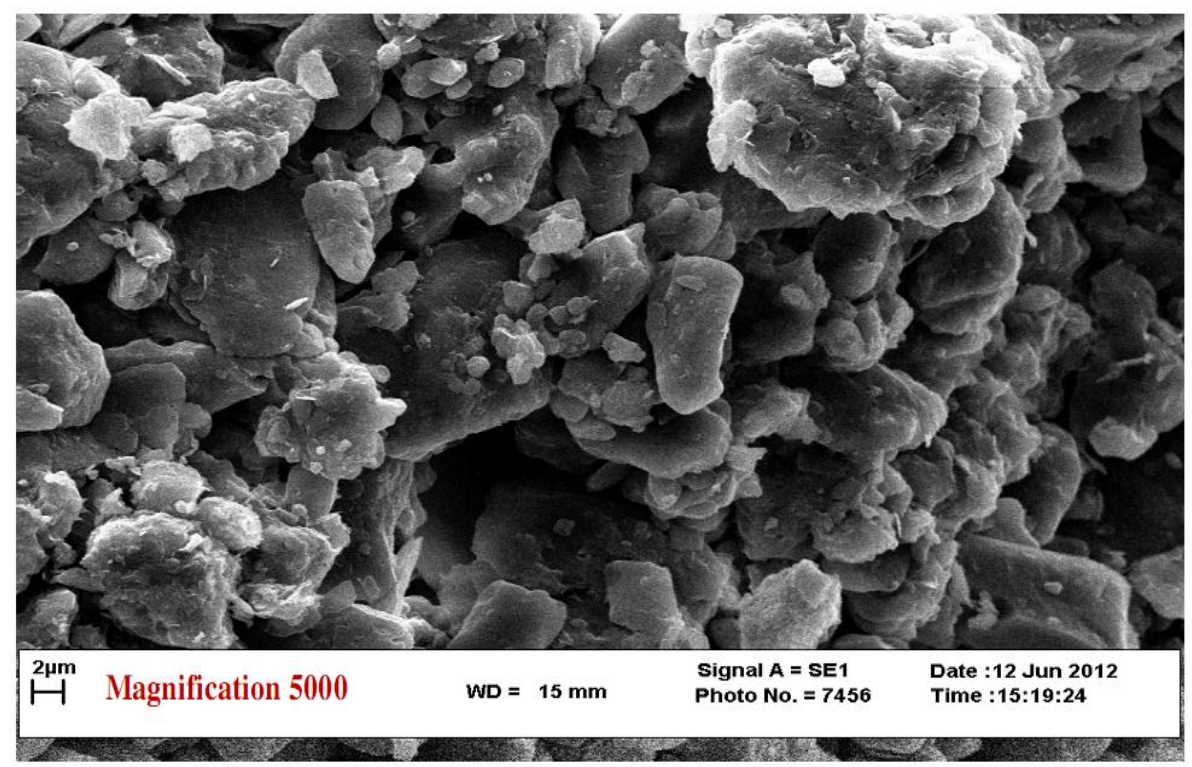

Figure- 10. Photomicrographs of reconstituted sample in forensic medicine site, depth $10 \mathrm{~m}$

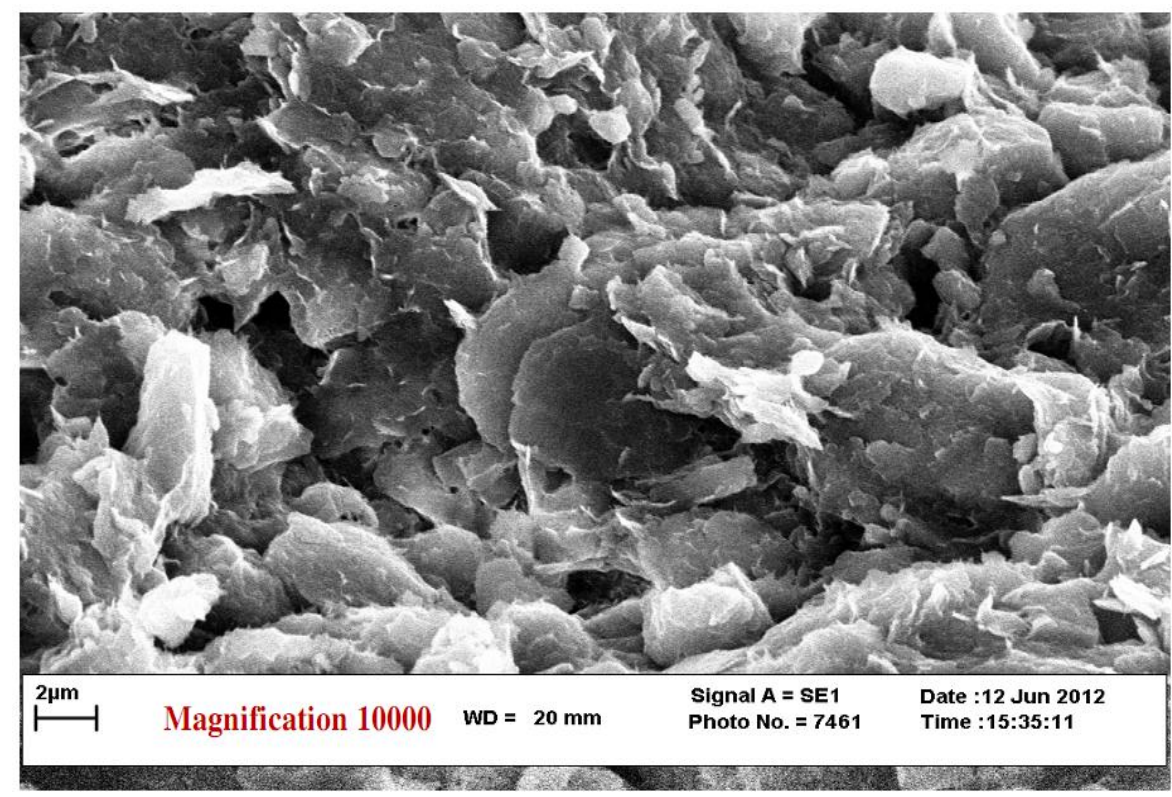


Figure- 11. Photomicrographs of reconstituted sample in forensic medicine site, depth $14 \mathrm{~m}$

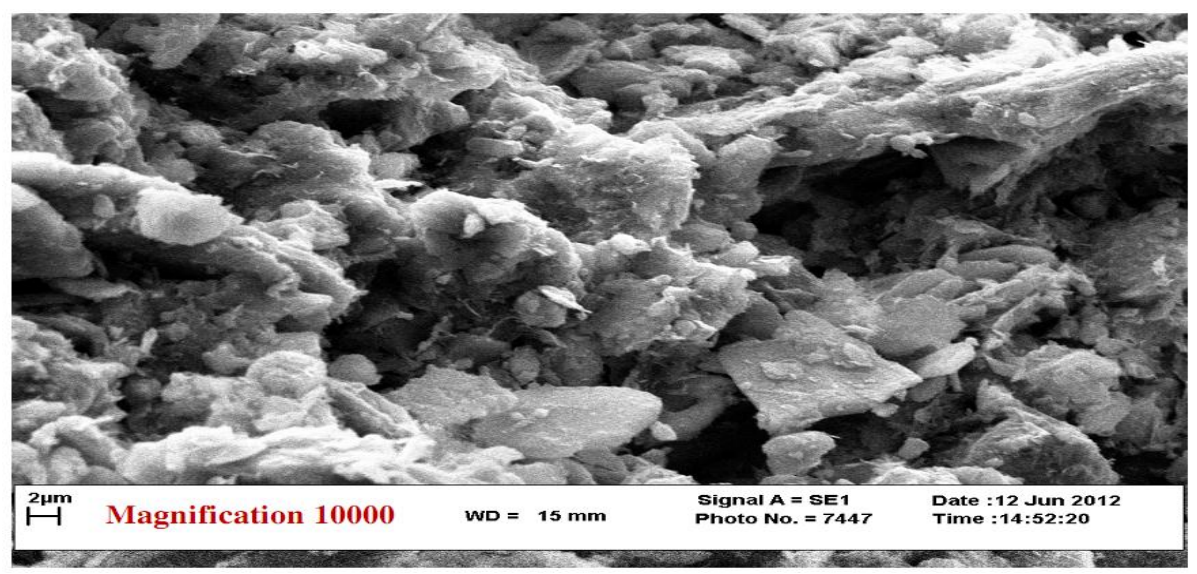

Figure- 12. Photomicrographs of undisturbed sample in forensic medicine site, depth $30 \mathrm{~m}$

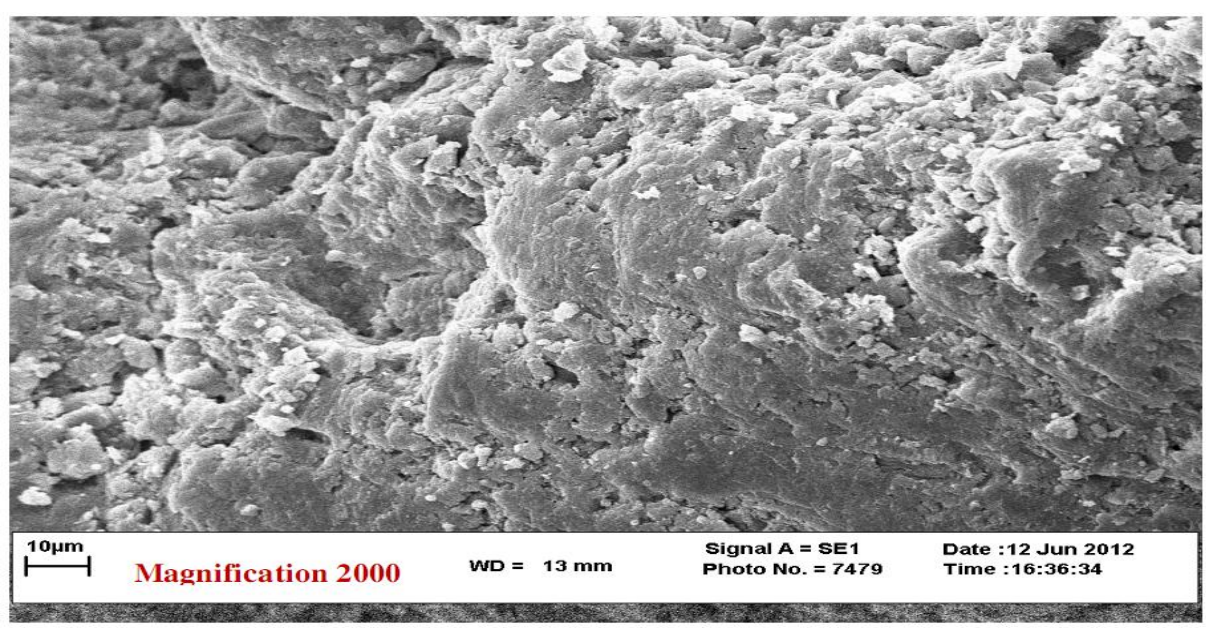

Figure- 13.Photomicrographs of undisturbed sample in Kusar four way site, depth $24 \mathrm{~m}$

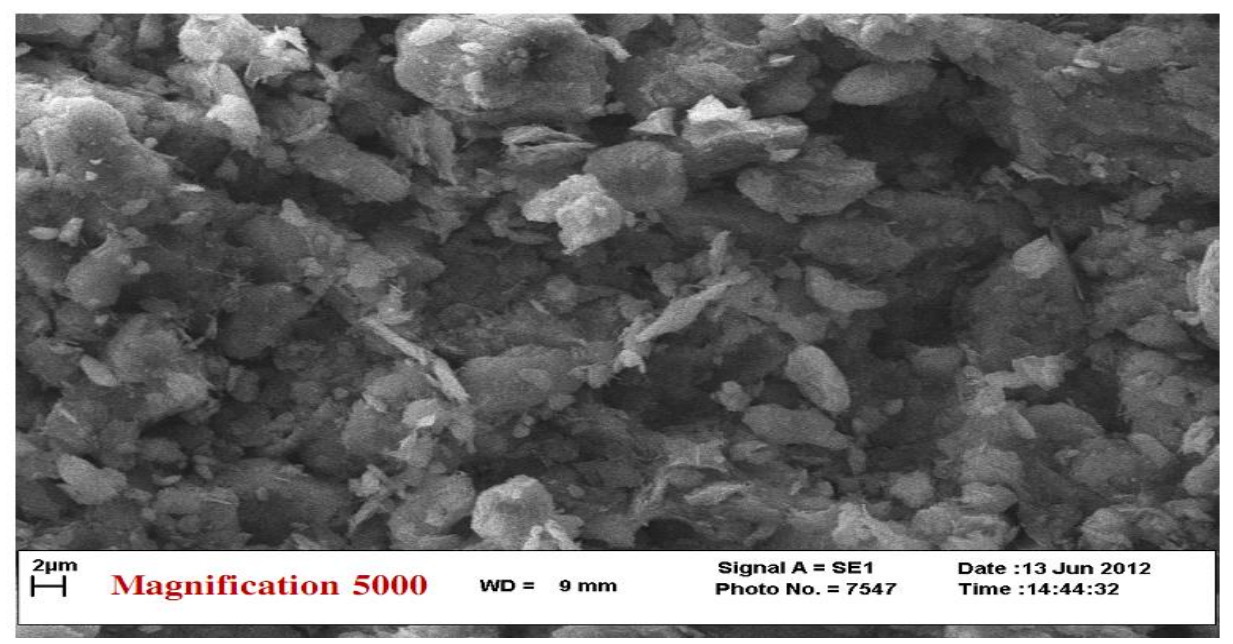


Figure- 14. Photomicrographs of undisturbed sample in Council park site, depth 40m

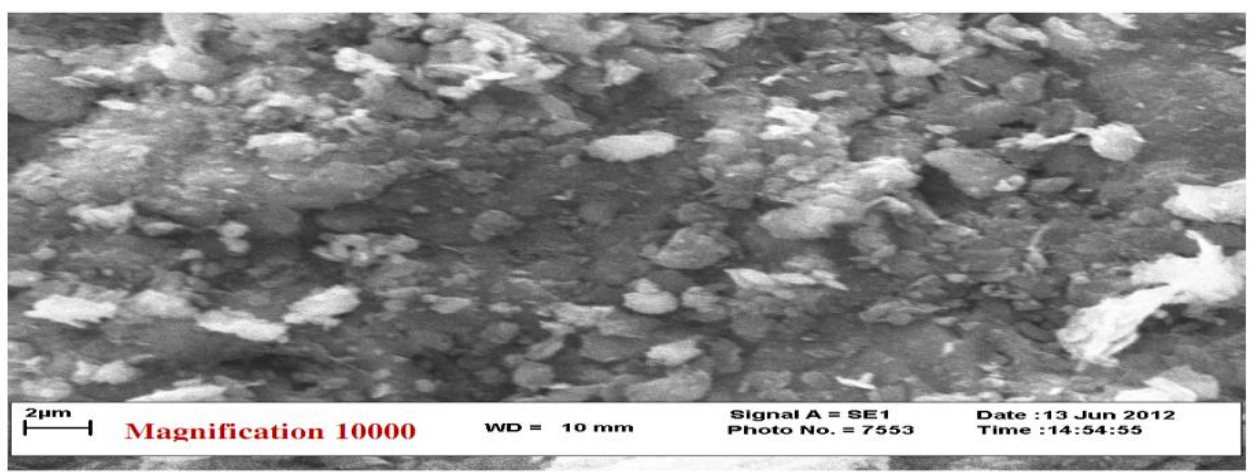

\subsection{Assessment of Physical Characteristics and Soil Plasticity in Kerman}

One of the defining parameters of clay minerals reconnaissance is plastic properties represented by the plasticity chart (Rahimi, 2005). Information of plasticity chart as the basis of fine-grained soils classification is very important. The plasticity chart of Kerman city soils is shown in figure (15). Figure (16) shows the position of different clay minerals on Casagranda plasticity chart. The comparison of plasticity chart in Kerman range soils has shown that the mineral contents are mainly Illite, Halloysite, Chlorite and montmorillonite. Figure (17) shows the plastic limit and liquid limit variation of Kerman soils in terms of depth. As can be seen there is not a certain correlation between these parameters and depth that reflects the relative uniformity and homogeneity in Kerman sedimentary deposits.

Figure- 15. Plasticity chart related to Kerman city range deposits.

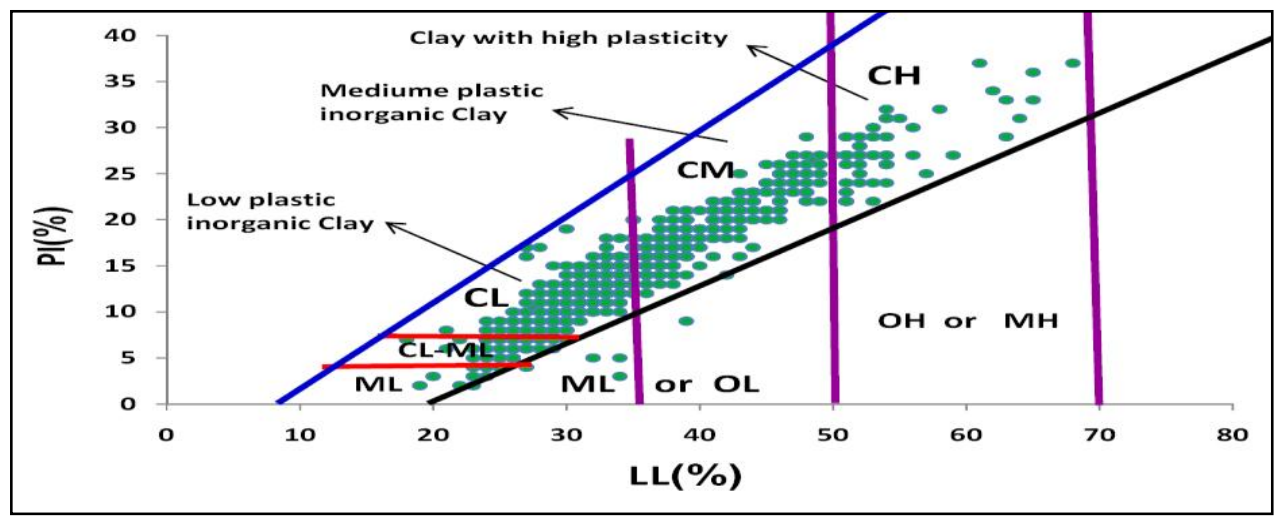

This subject shows the effectiveness of sedimentary basin on deposited soils in Kerman city and confirms that the Kerman city sediments deposited in short period and have been consolidated under the influence of in situ stresses exerted by upper surcharge. 
Figure- 16. Limits of clay minerals on Casagranda chart

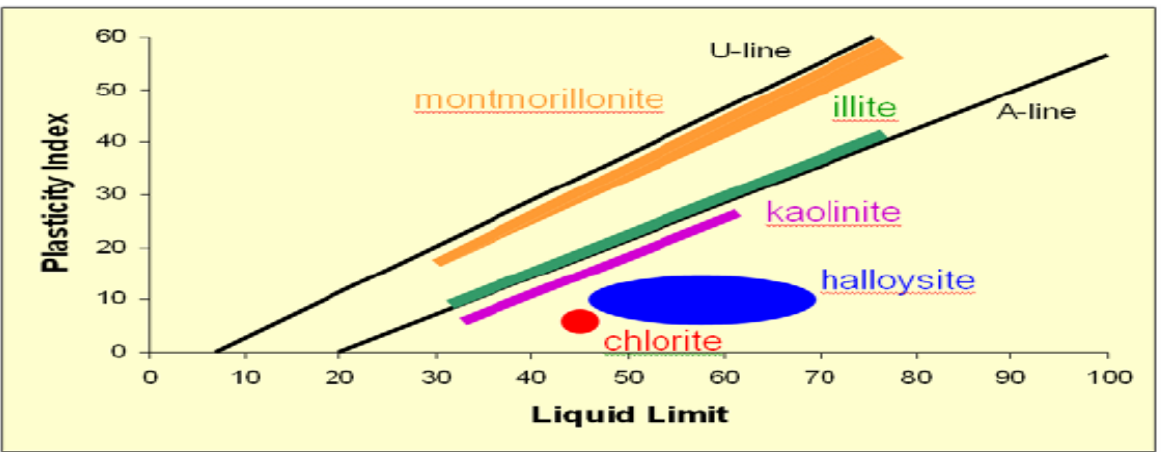

Figure- 17. Relationship between liquid limit and plasticity index with depth in Kerman city soils

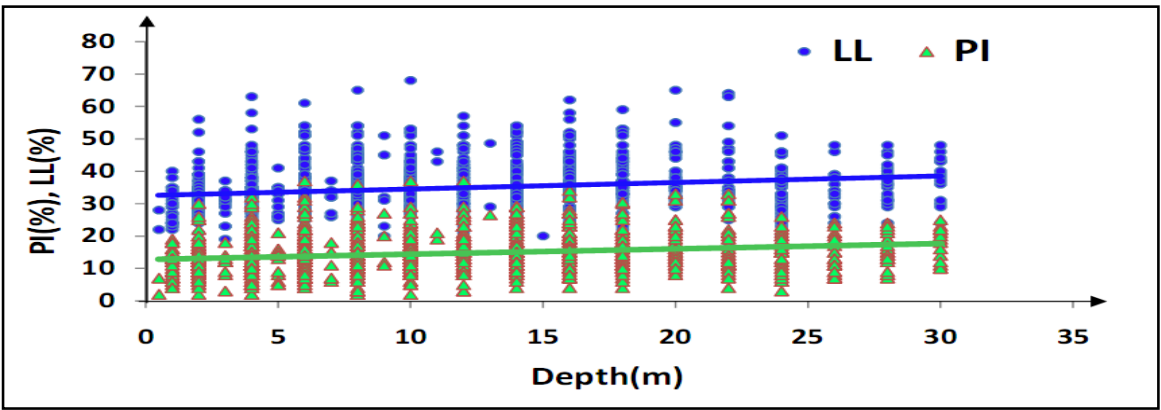

\subsection{Particle Size Distribution Curve of Kerman Soils}

To assess the particle size distribution of Kerman confine, 257soil data samples related to various sites of Kerman city arena were collected and the equivalent particle size distribution curve was extracted (figure 18). Grain size distribution curves of Kerman soils shows that the size of particles typically is less than half a millimeter. The main size of particles that were passing of mesh 200 is about 80 percent of soil weight.

Figure- 18. Equal particle size distribution curve of Kerman city confine

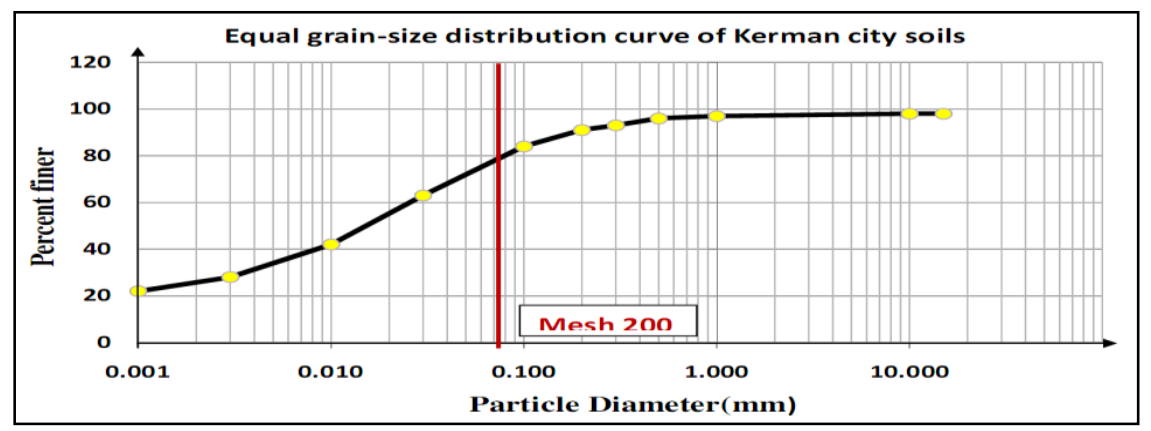

\subsection{Soil Classification in Kerman city Range}

For assessment of soil classification in the Kerman range soils, 1297 numbers of data collected and the frequency soil classes were calculated. Overall, Kerman city range is covered 
with fine grained soils until depth of 30 meter. The depth by which the soil classes has been studied, the most abundant soil class with no significant change belongs to CL-class or soils with low plasticity (Figure 19). Therefore all soil types in Kerman to depth of 30m have a high uniformity (Figures 20 to 22). The reason of uniformity is due to the effect of sedimentary basin on deposition of Kerman city range which causes high uniformity of soils.

Figure- 19. Frequency of soil classes based on unified classification

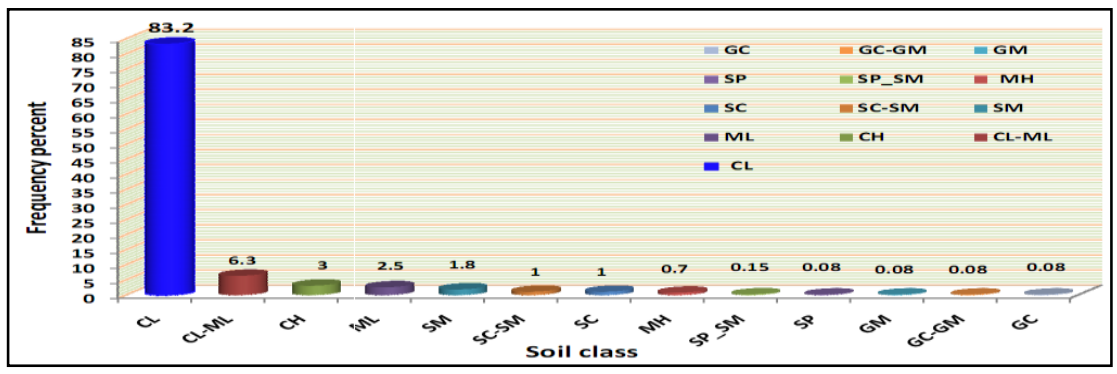

Figure- 20. Distribution maps of soil classes in Kerman city area in depth of 26 meters

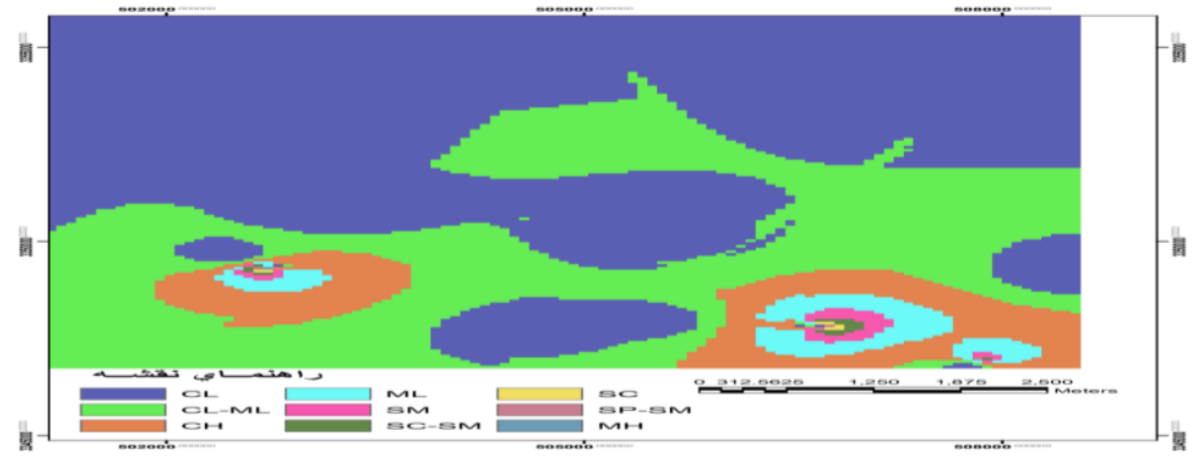

Figure- 21. Distribution maps of soil classes in Kerman city area in depth of $8 \mathrm{~m}$

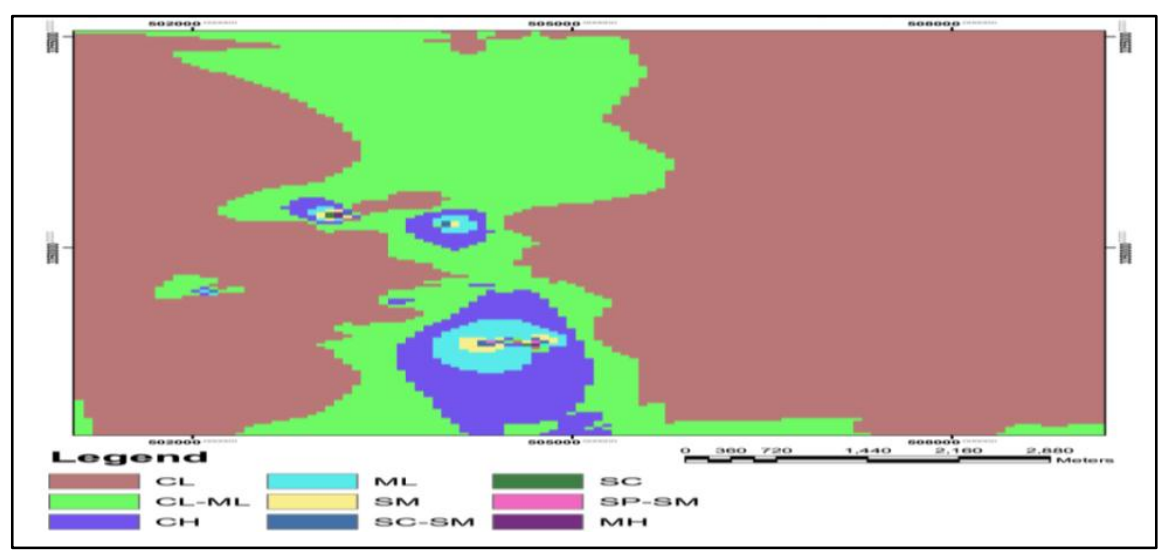


Figure- 22. Distribution maps of soil classes in Kerman city area in depth of $16 \mathrm{~m}$.

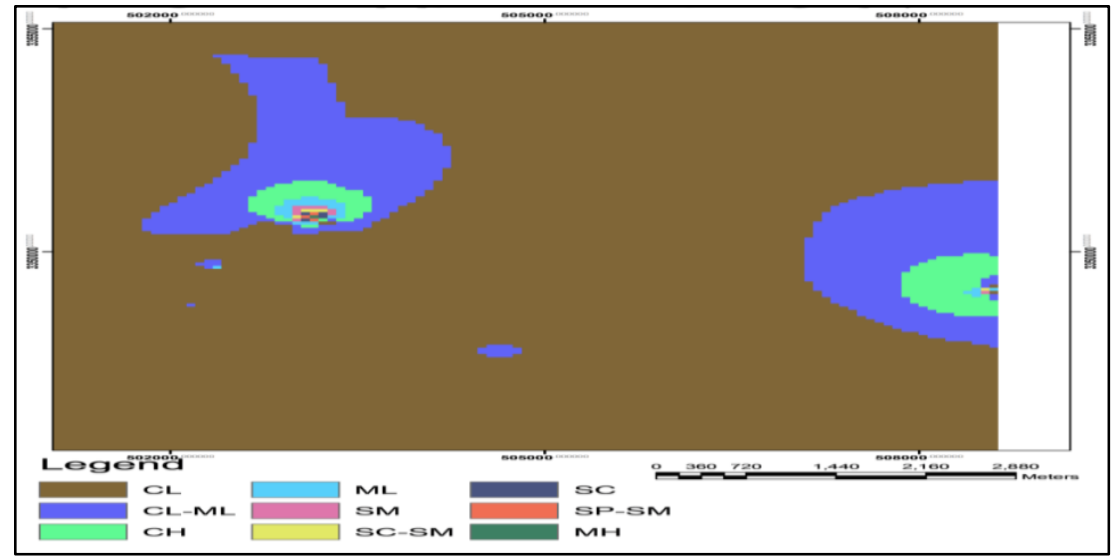

\section{CONCLUSIONS}

Result of mineralogical studies in Kerman city range indicates that the minerals present in sediments includes illite, chlorite, smectite, halloysite, illite - smectiteand and calcite. Abundance ratio of illite, smectite and chlorite minerals are nearly identical and the mentioned minerals have formed the major part of sedimentation deposit minerals in Kerman city arena. Calcite minerals in the sediments of Kerman can be seen as different forms. Sometimes as single crystal and sometimes in form of calcite nodules with cement present between the particles.

Moreover, evaluating results of scanning electron microscopy (SEM) images confirmed the compaction and dense arrangement of soil particles in the Kerman range. The soil grains generally have a connection of corner to corner and there is not a certain discipline in their structure; furthermore, the arrangement of the particles is random and chaotic. One of the most important factors in the arrangement of particles during soil deposition is the chemical state of sedimentary environments. Depositional environment of the Kerman basin has been fresh water and as a result the particles have been deposited in form of flocculate structure. But after deposition of particles, chemical effect of water was changed and soil structure influenced the condition of depositional environment and soil particles were mostly formed in random and house book arrangement. In addition to soil particles, the voids and pore spaces in soil structure also have been randomly distributed and are chaotic. Besides, the size of pore spaces is small and confirms that the soil structure is dense and compacted. In Kerman deposits the SEM results indicated a lower specific direction.

Bonds between the particles of soil that have established part of the soil strength and its sensitivity are in form of calcite cementation. Part of the calcite cement probably is a result of Plagioclase decomposition and the release of $\mathrm{Ca}+2$ ions and subsequently creates the carbonate cement. In some SEM images clear calcite grains are seen as single crystal. Besides the calcite particles can be seen as calcareous nodules that are visible in significant amount in form of different layers on Earth's surface. These nodules probably are the result of capillary phenomena 
and rising water. In general, the origin of the main part of Kerman soils is destruction of rocks with calcareous origin.

Finally, general review of SEM images shows that cementation has not been developed in Kerman city soils and soil grains are more compressed and compacted. Moreover, the uniformity of all soil types in Kerman to depth of $30 \mathrm{~m}$ that have been studied is high. The reason of uniformity is due to the effect of sedimentary basin in Kerman city range. Because Kerman sedimentary basin during the Pleistocene periods used to be as a shallow closed basin which received all sediments carried by flood processes originated from high mountains. During the Wurm glacial period due to upper Pleistocene movements, however, the Kerman sedimentary basin lost the closed basin condition and gently sloped to the North and North West direction and deposited sediments gradually shifted along downstream. So it is concluded that the present deposits of Kerman plain has been consolidated by the upper layers that are shifting in downstream now.

Funding: This study received no specific financial support.

Competing Interests: The authors declare that they have no competing interests.

Contributors/Acknowledgement: All authors contributed equally to the conception and design of the study.

\section{REFERENCES}

Amjad, S., R. Mousaviharami, M. MahmoudiGharaey, A. Mahbobi and H. Alizadehlahijani, 2011. Clay mineralogy of sediments of the continental shelf Available at the Gulf of Oman in Chabahar zone and its relationship to the origin of sediments. Journal of Oceanography, 2(8): 1-10.

Bressani, L.A., 1990. Experimental properties of bonded soils. PhD thesis. University of London.

Buscarnera, G. and R. Nova, 2011. Saturation induced instability on bonded geomaterials, Unsaturated Soils Alonso\& Gens (eds). Taylor \& Francis Group, London, ISBN 978-0-415-60428-4

Ciro, P., F. Roberto, M.P. Tácio and A. Franklin, 2011. Experimental and theoretical study of a gneiss young residual soils. EJGE, 16: 1185-1203.

Coop, M.R. and J.H. Atkinson, 1993. The mechanics of cemented carbonate sands. Geotechnique, 43(1): 5367.

Ehrmann, W., M. Setti and L. Marinoni, 2005. Clay minerals in Cenozoic sediments off Cape Roberts (McMurdo Sound, Antarctica) reveal the paleoclimatic history. Palaeogeography, Palaeoclimatology, Palaeoecology, 229(3): 187-211.

Haeri, M.S., A. Hamidi, S.M. Hosseini, E. Asghari and D.G. Toll, 2006. Effect of cement type on the mechanical behavior of a gravely sand. Geotechnical and Geological Engineering, 24(2): 335-360.

HosseiniBarzi, M., 2010. Spatial and temporal diagenetic evolution of syntectonic sediments in a pulsatory uplifted coastal escarpment, evidenced from the Plio-Plistocene, Makransubduction zone, Iran.Geological Society, London, Special Publications, 330: 273-289.

Huang, T.J. and W.D. Airey, 1991. The manufacture of cemented carbonate soils. School of Civil and Mining Engineering University of Sydney, Research Report No. 631. 
Kadjar, M.H., Nazemzadeh, M., Azizan, H., and Rowshanravan, J., 1996. The history of Kerman Basin during the Neogene and Quaternary, GSI, Regional Center for S.E. Iran (Kerman), Research Report No. 1: 74 .

Khoddami, M., A. Mahbobi, S. Faiznia, R. Mousaviharami and F. Fattahiardakani, 2006. Applications of clay minerals as indicators of erosion: an example from Latshvr basin. South-East of Tehran. Journal of Crystallography and Mineralogy of Iran, 14(2): 247-262.

Maccarini, M., 1987. Laboratory studies of a weakly bonded artificial soil. PhD thesis, University of London.

Rahimi, H. 2005. Soil mechanics, 2nd Edn., Science and Technology Press. pp: 622.

Richard, J.M., 2005. Clay minerals and sedimentary basin history. Eur. J. Mineral, 17(1): 7-20.

Thomas ,M. F., 2003. Late quaternary sediment fluxes from tropical watersheds, Sedimentary Geology, 162(1-2): 63-81.

Welton, J.E., 1950. SEM petrology atlas,. Published by the American Association of petroleum Geologist, Tulsa, Oklahoma, USA. pp: 236. 